\title{
MAPS SHOWING THE SURFICIAL GEOLOGY OF THE CULEBRA SHELF, PUERTO RICO \\ by
}

Monty A. Hampton1, Michael E. Torresan1, Juan L. Trias2, David W. Folger3, and Florence L. Wong1

1U.S. Geological Survey, Menlo Park, CA 2U.S. Geological Survey, San Juan, PR 3U.S. Geological Survey, Woods Hole, MA 1997

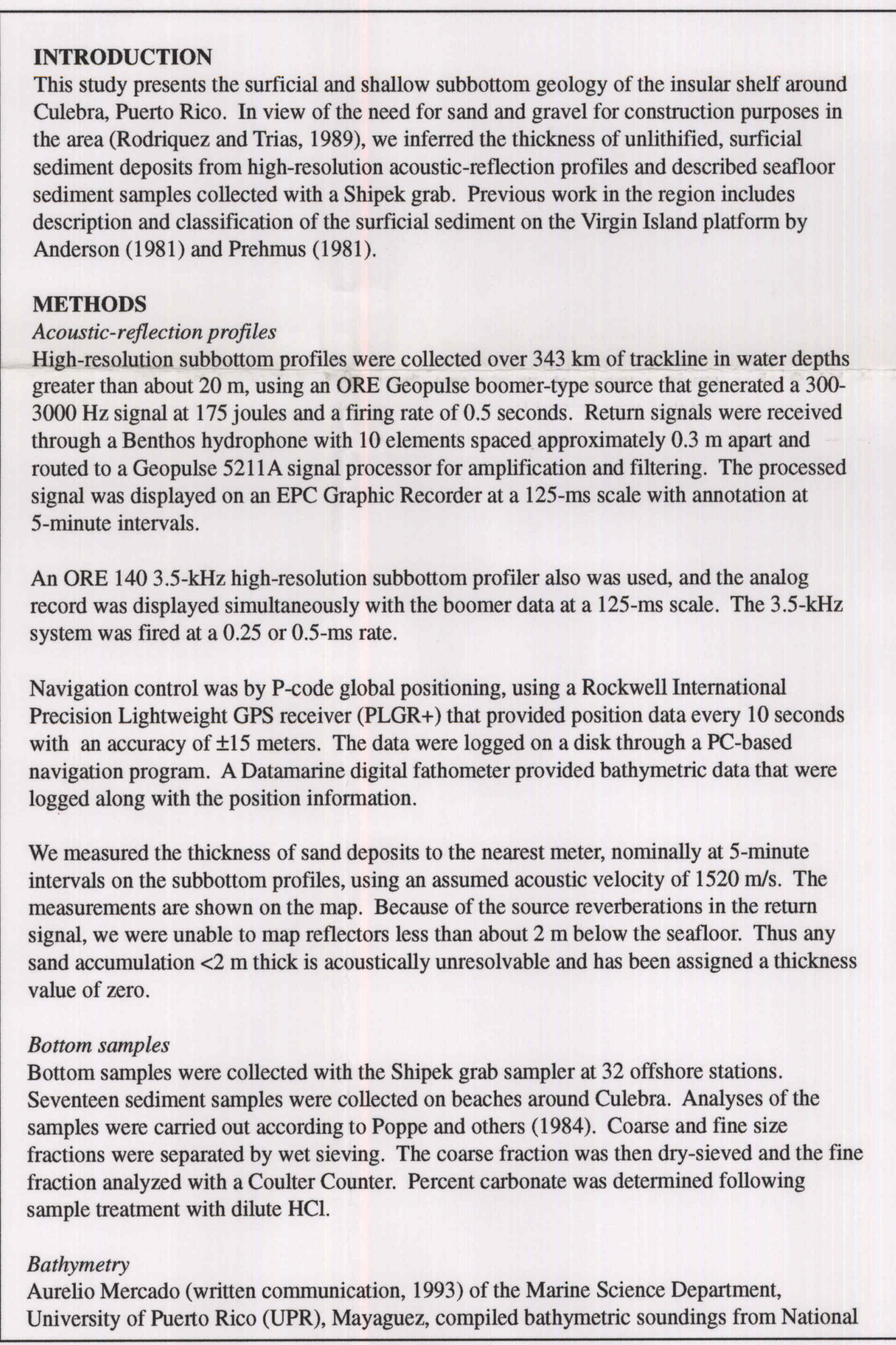

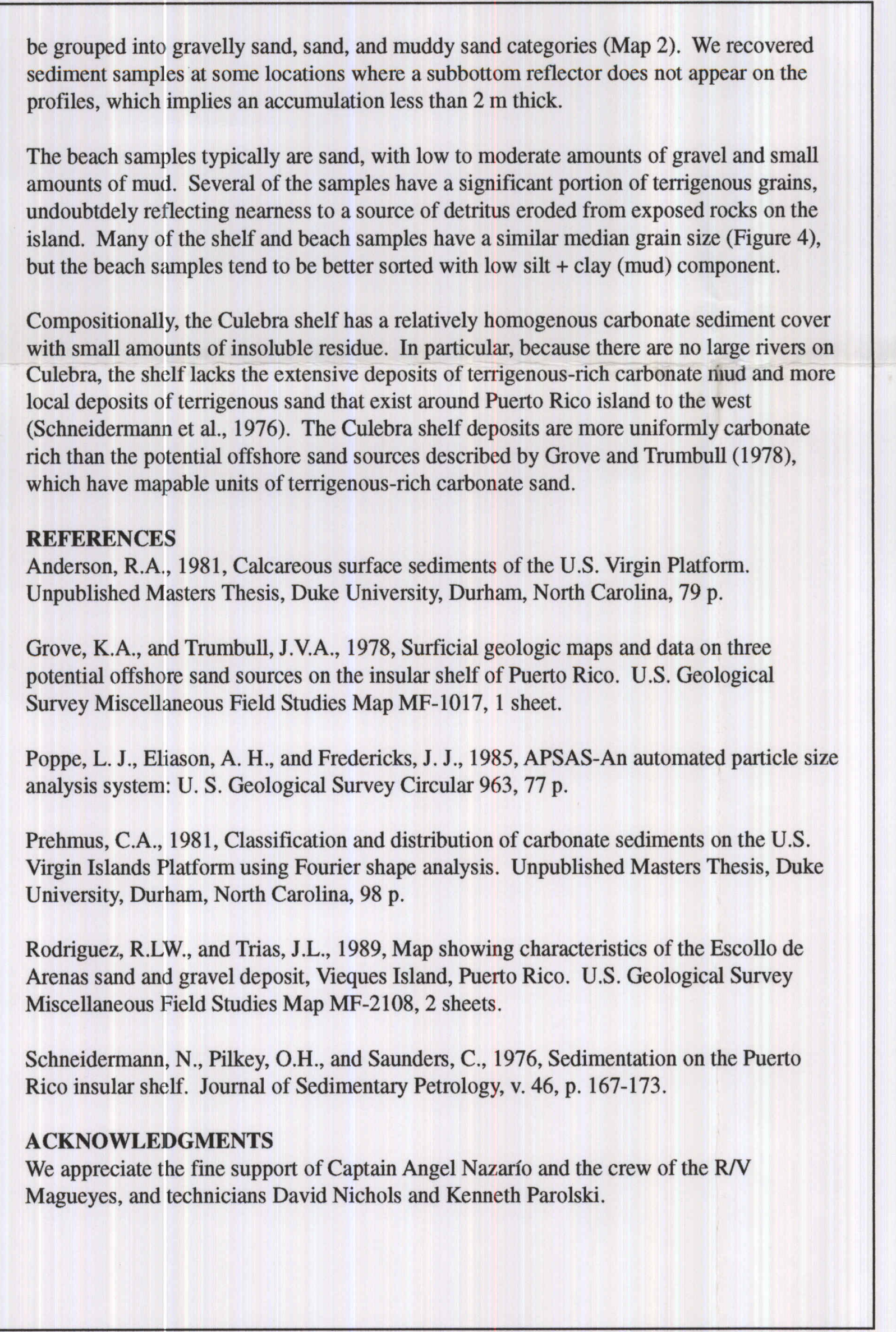
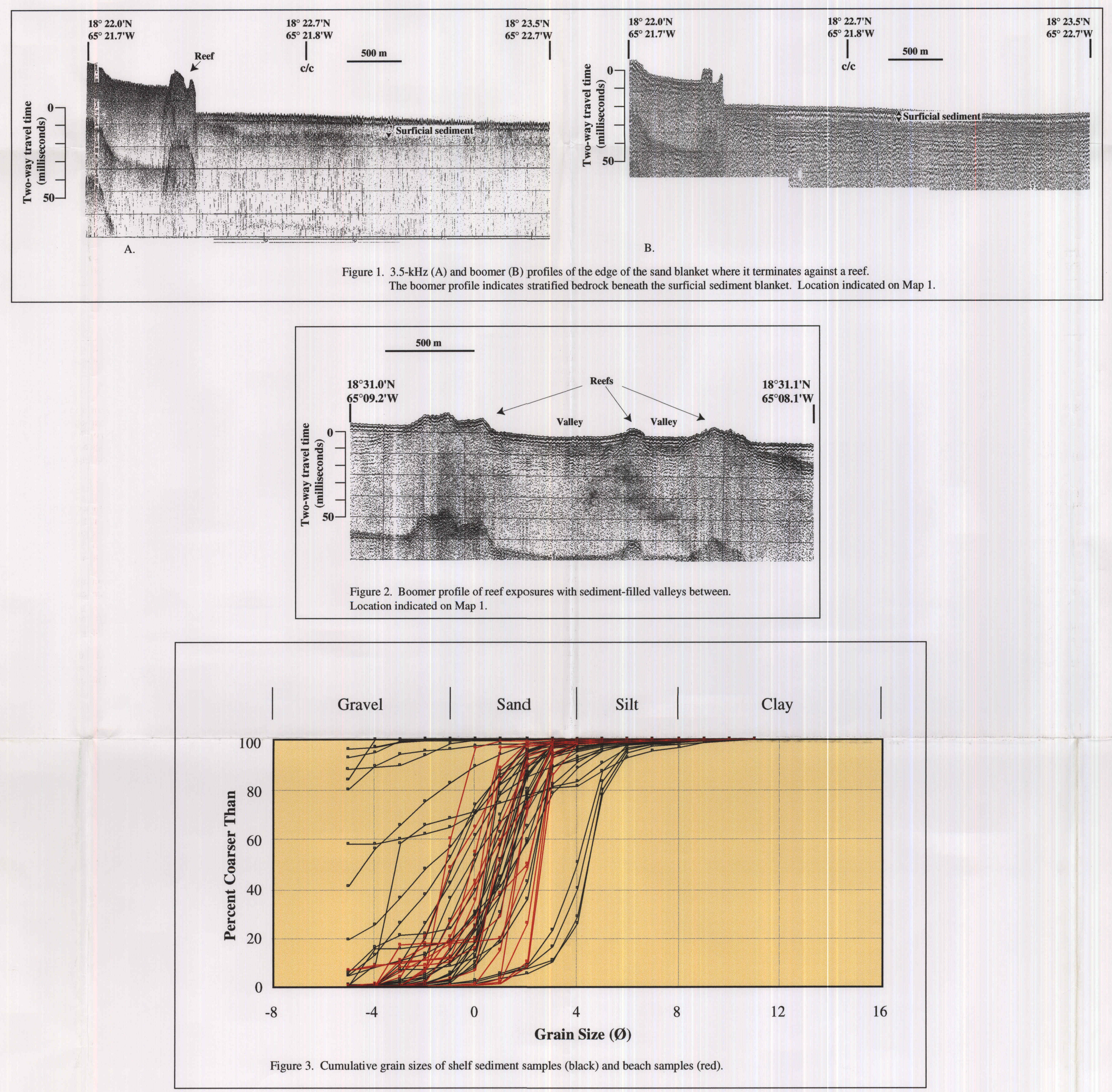

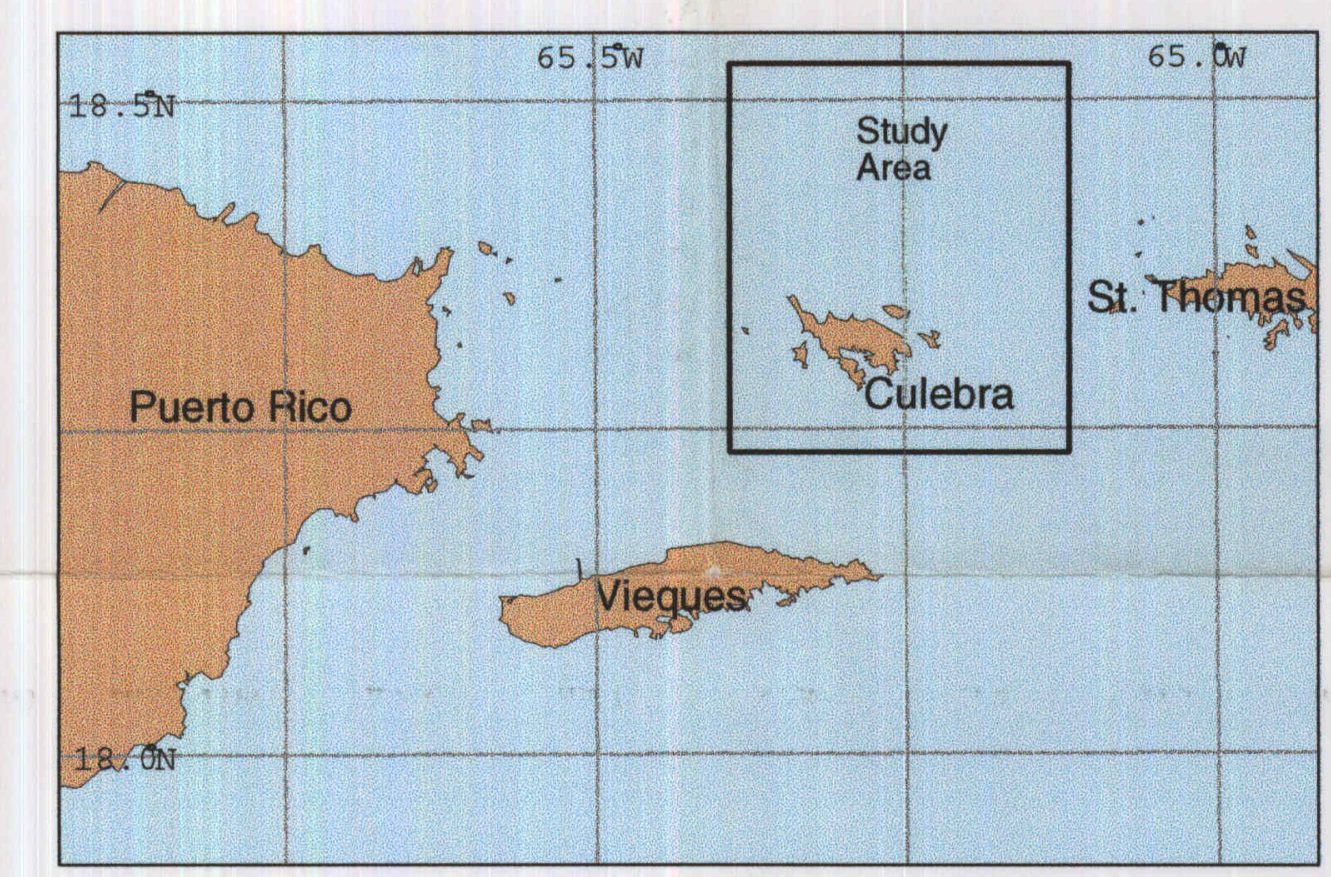

Table 1. Location, exture, and composition of offishore samples
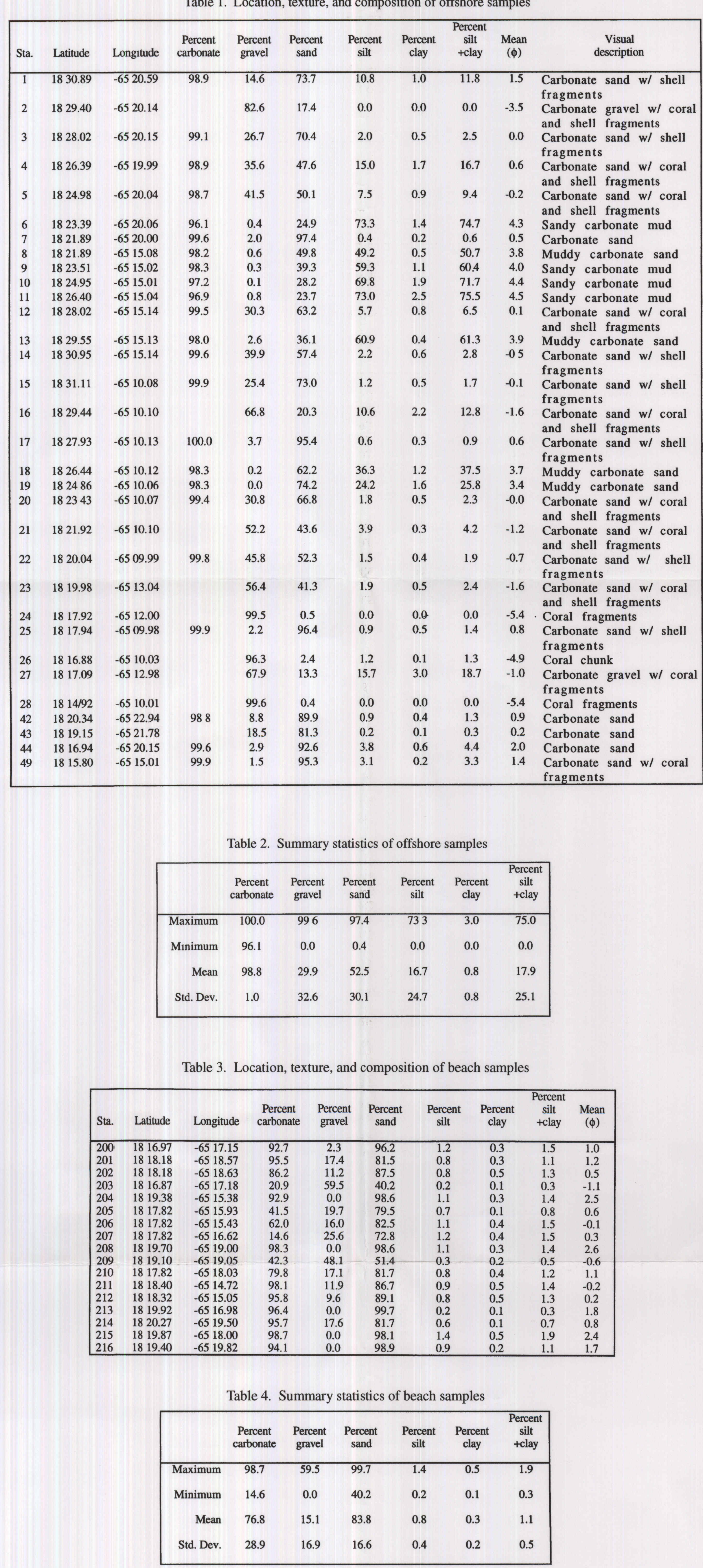